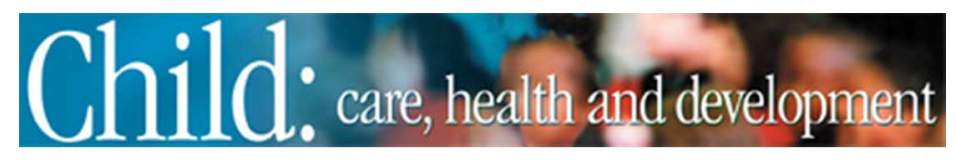

\title{
Tertiary paediatric hospital admissions in children and young people with cerebral palsy
}

\begin{tabular}{|r|l|}
\hline Journal: & Child: Care, Health \& Development \\
\hline Manuscript ID: & CCH-2014-0383.R1 \\
\hline Manuscript Type: & Research Article \\
\hline Keywords: & $\begin{array}{l}\text { Hospitalisations, Readmissions, Respiratory, Health Services Research, } \\
\text { Inpatient resources, Cerebral palsy register }\end{array}$ \\
\hline \multicolumn{2}{|l}{} \\
\hline
\end{tabular}

\section{SCHOLARONE ${ }^{\text {Tw }}$ \\ Manuscripts}


Tertiary paediatric hospital admissions in children and young people with cerebral palsy

\begin{abstract}
Background

Many previous studies that have investigated hospital admissions in children and young people with cerebral palsy lack information on cerebral palsy severity and complexity. Consequently, little is known about factors associated with the frequency and type of hospital admissions in this population. This study used hospital admission data available for all children and young people known to a population-based cerebral palsy register to describe the patterns of use of tertiary paediatric hospital services over a five-year period.
\end{abstract}

\title{
Methods
}

This was a retrospective cohort analysis of routinely-collected admission data from the two tertiary paediatric hospitals in the Australian state of Victoria. Data on admissions of individuals born between 1993 and 2008 registered on the Victorian Cerebral Palsy Register were analysed $(n=2,183)$.

\section{Results}

Between 2008 and 2012, 53\% of the cohort $(n=1,160)$ had at least one same-day admission and $46 \%$ $(n=996)$ had one or more multi-day admissions. Those with a moderate to severe motor impairment and those with a co-diagnosis of epilepsy had more admissions, and for multi-day admissions, longer lengths of stay; $p<0.05$. Across all severity levels, respiratory and musculoskeletal diseases were the most frequently reported reasons for medical and surgical admissions respectively. All-cause readmission rates for urgent multi-day stays within 7-, 30- and 365-days of an index admission were $10 \%, 23 \%$ and $63 \%$ respectively.

\section{Conclusions}

The reasons for hospital admissions reported here reflect the range of comorbidities experienced by children and young people with cerebral palsy. This study highlights priority areas for prevention, early diagnosis and medical management in this group. Improved primary and secondary prevention measures may decrease non-elective hospital admissions and readmissions in this group, and reduce paediatric inpatient resource use and healthcare expenditure attributable to cerebral palsy.

\section{Key points}

- Those with a mild motor impairment were more frequently admitted to hospital for factors relating to their movement problem; the administration of botulinum toxin-A injections comprised a substantial proportion of same-day admissions in independently ambulant children and young people.

- Although musculoskeletal conditions represented the most common reason for surgical admissions in children with moderate-severe motor impairment, disorders of the nutritional and respiratory systems also represented a substantial proportion of both surgical and nonsurgical admissions in this group.

- For clinicians involved in managing patients with cerebral palsy, respiratory health should continue to be an important focus and where possible, preventive measures should be implemented to reduce respiratory-related morbidity and subsequent hospital admissions. 


\section{Introduction}

Cerebral palsy (CP), a disorder of movement and posture resulting from an injury or disturbance to the developing brain (Rosenbaum et al. 2007), is the most common cause of permanent physical disability in children. It affects around 2 per 1,000 live births in developed countries worldwide, its prevalence inversely associated with gestational age (Oskoui et al. 2013). Affected children can experience frequent illness due to their increased risk of epilepsy, gastrointestinal and nutritional problems, and respiratory disorders compared to the general childhood population, with those children who are the most severely motor impaired at the greatest risk (Pruitt and Tsai 2009, Shevell et al. 2009). Furthermore, children with CP are at risk of developing progressive musculoskeletal pathologies (Graham and Selber 2003), and many are technology dependent, including around one in ten reliant on a gastrostomy feeding tube (Dahlseng et al. 2012).

The proportion of all paediatric hospital admissions attributable to chronic health conditions has increased over the past few decades, the reasons for which are multifactorial (Simon et al. 2010, Berry et al. 2012b). The increased prevalence of children with such conditions in the population today, due to advances in neonatal medicine and the increased survival of children born pre-term or with life-limiting conditions (Doyle and the Victorian Infant Collaborative Study Group 2004, Kaiser et al. 2004), may be playing a role. Other factors, including the increasing number of surgical procedures performed on these children, and the scarcity of community-based medical professionals that can manage paediatric chronic illness in many regions, are also implicated (Berry et al. 2012a). In addition to having more hospital admissions than their typically-developing peers, previous research tells us that children and young people with CP are more likely to die during a hospital admission, experience longer lengths of stay, have more diagnoses and undergo more procedures per admission, and accrue higher hospital charges (Young et al. 2007, Murphy et al. 2006). This group are also more likely to experience recurrent readmissions to hospital (Berry et al. 2011), with the associated significant costs for health services and for patients and their families (Nakamura et al. 2014). Disorders of the respiratory and nervous systems have been reported to account for the majority of hospital admissions in this population, followed by disorders of the musculoskeletal and gastrointestinal systems (Murphy et al. 2006, Young et al. 2011).

Overall, studies that have examined inpatient resource use specifically in the CP population are scarce, and are limited by a number of factors including the inclusion of particular age-groups only (Young et al. 2007, Young et al. 2011), the use of diagnosis codes to identify individuals with CP (Murphy et al. 2006), and a lack of clinical information on CP severity and complexity (Murphy et al. 2006, Young et al. 2011). This study used hospital admission data available for all children and young people known to a population-based CP register to evaluate the main reasons for tertiary paediatric hospital admissions in this group and to identify clinical factors associated with the frequency and type of admissions. Secondary aims were to identify factors associated with multi-day length of stay and 7-, 30- and 365-day rates of all-cause readmissions.

\section{Methods}

\section{Study design and setting}

This study was a retrospective cohort analysis of routinely-collected admission data from the two tertiary paediatric hospitals in the Australian state of Victoria: the Royal Children's Hospital, Melbourne (RCH) and Monash Children's Hospital $(\mathrm{MCH})$. Data pertaining to the same-day and multi-day admissions of all individuals born between 1993 and 2008 registered on the Victorian Cerebral Palsy Register were included for analysis. The Victorian Cerebral Palsy Register is a database of individuals with CP born or living in Victoria, born from 1970 onwards. Clinical and demographic data on registered cases is obtained primarily from the medical records, but also from families and treating clinicians. The study was approved by the Human Research Ethics Committees of both hospitals; a waiver of informed consent was granted. 


\section{Procedures}

For each member of the cohort, data were obtained on admissions to $\mathrm{RCH}$ and $\mathrm{MCH}$ between 2008 and 2012. Health Information Services personnel from both hospitals were provided with a list of the hospital unit record numbers of all members of the cohort, following which they extracted the relevant data. Variables included admission date, discharge date, same-day flag, admission type (emergency, elective, other), primary diagnosis code, secondary diagnoses codes, primary procedure code, Australian Refined Diagnostic Related Groups (AR-DRG), and local government area of residence. Variables available from the $\mathrm{CP}$ register included date of birth, epilepsy status and Gross Motor Function Classification System (GMFCS) level. The GMFCS is a five-level classification tool, used to describe the gross motor abilities of individuals with CP on the basis of their self-initiated movement with particular emphasis on sitting, walking, and wheeled mobility across four age bands: $\mathrm{I} / \mathrm{II}=$ independently ambulant; III = ambulates with aids; IV-V = not independently ambulant (Palisano et al. 1997). Epilepsy was defined as two or more unprovoked seizures outside the neonatal period.

The standard grouping of International Statistical Classification of Diseases and Related Health Problems $10^{\text {th }}$ Revision (ICD-10) codes was used to categorise the principal diagnosis for each admission (World Health Organisation 2011). The analysis focused on the primary diagnoses only. In a small number of cases, CP was listed as the primary diagnosis and a secondary diagnosis was available; in these cases, the secondary diagnosis was used. If no secondary diagnosis was available, $\mathrm{CP}$ was used. Primary procedures were categorised using the Australian Classification of Health Interventions $(\mathrm{ACHI})$, the national standard for procedure and intervention coding in Australian hospitals (Commonwealth of Australia 2010). The AR-DRG, an Australian admitted patient classification system which provides a clinically meaningful way of describing a hospital's case-mix, was used to differentiate between surgical and medical admissions (Australian Institute of Health and Welfare 2014).

Every admission was counted as a separate index admission, and was the starting point for follow-up to check for readmissions. An admission did not require a "clean period" with no admissions to constitute an index admission. As such, an admission could be both a readmission for a prior admission, and the index admission for a subsequent readmission. A readmission was defined as a subsequent multi-day admission for any diagnosis within 7, 30 or 365 days of the discharge date of an index admission. For 7-day readmissions, the discharge date for the index admission must have occurred prior to $24^{\text {th }}$ December 2012, and for 30-day and 365-day readmissions the discharge date must have occurred prior to 1 December 2012 and 31 Dec 2011 respectively. This approach ensured adequate follow-up periods.

\section{Statistical analysis}

Descriptive statistics were used to summarise the study cohort and admission characteristics. GMFCS levels were dichotomised (levels I-II as mild motor impairment, and levels III-V as moderate to severe motor impairment). Mann-Whitney tests were used to investigate differences in the total number of admissions and in length of stay for multi-day admissions (which both demonstrated a non-normal distribution pattern) across the dichotomous categories of GMFCS, epilepsy and AR-DRG type. Primary diagnoses and procedures were tabulated, and chi squared analysis was used to test for equality of percentages between GMFCS sub-groups. Chi-squared analysis was also used to test for variation in readmission rates between GMFCS sub-groups. Readmission rates were calculated by dividing the total number of multi-day stays with at least one subsequent hospital stay within $7 / 30 / 365$ days by the total number of multi-day stays that took place over the relevant time period. P-values were defined as the probability that differences between sub-groups as large as, or larger than, that observed in this cohort could have arisen due to random chance alone; a value of less than 0.05 was considered to provide strong evidence of difference. All data analysis was carried out using Stata 13.1 (StataCorp. 2013). 


\section{Results}

\section{Study cohort}

The cohort comprised 2183 children and young people with CP. Fewer than $5 \%(n=102)$ were aged 04 years in December 2012, and 32\%, 33\% and 31\% were aged 5-9, 10-14 and 15-19 years respectively. The proportions classified as functioning at GMFCS levels I, II, III, IV and V were 34\% $(n=750), 26 \%(567), 10 \%(n=223), 13 \%(n=277)$ and $13 \%(n=283)$ respectively; data on GMFCS was missing for $4 \%$ of the cohort $(n=83)$. Overall, $29 \%(n=623)$ had a co-diagnosis of epilepsy and $68 \%$ $(n=1476)$ did not; data on epilepsy was missing for approximately $4 \%(n=84)$ of the cohort.

Of the 2183 members of the CP cohort, 1443 (66\%) had $\geq 1$ tertiary paediatric hospital admission between 2008 and 2012. Overall, 53\% of individuals $(n=1,160)$ had $\geq 1$ same-day admission and $46 \%$ ( $n=996$ ) had $\geq 1$ multi-day admission. Compared to those who had had no admission over the study period, children and young people who had at least one admission were younger, and were more likely to have a co-diagnosis of epilepsy and to be classified as GMFCS III-V $(p<0.001)$.

\section{Total admissions}

Members of the CP cohort had a total of 7177 admissions. Fifty-two per cent $(n=3737)$ were sameday admissions, of which $92 \%(n=3444)$ were elective. Of the 3440 multi-day admissions, 52\% were elective $(n=1784)$. Factors strongly associated with a greater number of both same-day and multiday admissions were GMFCS level and epilepsy, with those children who were more severely motor impaired (GMFCS III-V) and those with a co-diagnosis of epilepsy having a greater number of admissions; $p<0.001$. (Table 1)

\section{Multi-day admissions}

Children classified as GMFCS III-V accounted for 68\% ( $n=2324)$ of all multi-day admissions, and $75 \%$ of the total number of admitted nights $(n=16523)$. The median length of stay for this group (4 days) was significantly longer than that of individuals classified as GMFCS I-II (2 days); $p<0.0001$. Of the 3,440 multi-day admissions, medical and surgical AR-DRGs were responsible for $48 \%(n=1636)$ and $37 \%(n=1269)$ respectively; the remainder $(15 \%)$ were comprised of other or unknown DRG types. (Table 2)

Respiratory diseases were the most frequently reported diagnoses for medical multi-day admissions across all GMFCS levels, but represented a higher proportion in children classified as GMFCS III-V compared to children classified as GMFCS I-II ( $24 \%$ vs $12 \%$; $p<0.001)$. Among surgical multi-day admissions, diseases of the musculoskeletal system were the most common primary diagnoses across all GMFCS levels, representing $47 \%$ and $43 \%$ of surgical multi-day admissions in children classified as GMFCS I-II and GMFCS III-V respectively. (Table 3)

\section{Procedures}

Musculoskeletal procedures represented the primary procedure in one-half $(n=1857)$ of all same-day admissions and one-quarter $(n=877)$ of all multi-day admissions. (Table 4) For same-day admissions, the administration of an agent (most frequently botulinum toxin-A) into a musculoskeletal site was the most common musculoskeletal procedure $(n=1757)$, while for multi-day admissions, procedures performed on the hip $(n=321)$ and leg $(n=211)$ were the most common. With the exception of musculoskeletal procedures and those categorised as "non-invasive, cognitive and other interventions", relatively few children classified as GMFCS I-II had other types of procedures carried out during admissions. In contrast, children classified as GMFCS III-V had a digestive system procedure in over $10 \%$ of all admissions, and were also more likely than those classified as GMFCS III to have had procedures related to the nervous system (3\%) and respiratory system (4\%). (Table 4) 


\section{Readmission rates}

For non-elective multi-day admissions, the 7-day, 30-day and 365-day readmission rates were $10 \%$, $23 \%$ and $63 \%$ respectively. GMFCS level was strongly associated with 30-day and 365-day admission rates, children classified as GMFCS III-V having significantly higher 30-day and 365-day readmission rates than those classified as GMFCS I-II. Admissions due to diseases of the digestive and respiratory systems had the highest rates of readmission. (Table 5)

\section{Discussion}

This study investigated the patterns of use of tertiary paediatric inpatient services by a population cohort of children and young people with CP. Key findings were that 1) children and young people who were more severely motor impaired and those who had a co-diagnosis of epilepsy experienced a greater number of admissions, and for multi-day admissions, had longer lengths of stay, 2) respiratory diseases and musculoskeletal conditions were the most common reasons for medical and surgical admissions respectively, 3) individuals classified as GMFCS I-II were more frequently admitted to hospital for factors relating to their movement problem, while nutritional needs and respiratory complications drove a substantial amount of both surgical and non-surgical admissions in those classified as GMFCS III-V, and 4) admissions due to diseases of the digestive and respiratory systems were among those with the highest rates of all-cause readmissions.

Studies reiterate the need for adequate information sharing between hospitals and communitybased healthcare professionals, and emphasise the benefits of care-coordination and accessible care plans in reducing medical service use in medically-complex children (Quigley et al. 2014, Adams et al. 2013, Antonelli et al. 2008, Cohen et al. 2012). However, the design of health systems is often such that the focus is on addressing acute episodes of care, and chronic disease management and care continuum are rarely prioritised (Quigley et al. 2014). When individuals require the resources that only inpatient care can provide, admission to hospital is appropriate. However, where possible, avoiding hospitalisations is desirable, given the disruption it causes to individuals and their families (Nakamura et al. 2014).

It is important that clinicians are aware of the most common reasons for hospital admission in individuals with CP and the risk factors for frequent admission, so that areas for prevention can be identified. While a certain amount of morbidity in this group is not preventable (e.g. musculoskeletal pathologies), it is important that factors that may have the potential to be changed (e.g. nutritional status and pulmonary aspiration risk) are identified and managed early (Murphy et al. 2006). Respiratory illness is the leading cause of mortality in individuals with CP (Reid et al. 2012), and the finding that it was the main reason for non-surgical hospital admissions in this CP cohort was not surprising. However, it does suggest that the respiratory health of children and young people with severe CP in particular should remain an important focus for clinicians and a priority area for research. While many factors that contribute to respiratory morbidity in this group are not avoidable, complications such as kyphoscoliosis and malnutrition should be monitored, and it is recommended that individuals with CP receive seasonal influenza vaccines, and that prophylactic antibiotics are considered in certain cases (McCrea et al. 2013).

Readmissions to hospital within 30 and 365 days of an index admission have been reported to occur in children at rates of around 6\% and 20\% respectively (Berry et al. 2011, Berry et al. 2013). Readmission rates in children with medical complexity are known to be higher, with one group reporting a 30 day readmission rate of $11 \%$ for children with CP and other neurological conditions (Berry et al. 2013). The 30 -day readmission rate of $23 \%$ in this study was higher than that previously reported in the literature. However, some of this variation may be accounted for by differences in methods of calculation, specifically differences in what defines an index admission, and whether or not readmissions for any cause or readmissions for the same diagnosis of the index stay were counted. Regardless, rates of readmission for all causes in this group were higher than expected. 
Traditionally viewed as indicators of care quality (Ashton et al. 1997), it is now accepted that readmission rates are affected by factors external to hospitals, and for reasons that are multifactorial (Alverson and O' Callaghan 2013, Bardach et al. 2013, Nakamura et al. 2014). Factors influencing paediatric readmissions include parent preferences, distance of the child's home from the hospital and availability of primary care and other health care services in the child's area of residence (Alverson and O' Callaghan 2013). As such, as well as ensuring children are well enough for discharge, high-quality discharge planning which takes these factors into account and adequate communication between hospitals, families and community-based health care practitioners involved in the care of these children, play an important role in preventing readmissions in the group. Given that reasons for readmissions are often different from the reason for the initial admission (Berry et al. 2013), it is important that post-discharge care planning focus attention not just on the primary diagnosis of the admission, but also on individuals' comorbidities.

\section{Strengths and limitations}

Potential inconsistencies in coding mean that diagnosis and procedure data need to be interpreted carefully. For example, for those admissions that had a discharge diagnosis of $\mathrm{CP}$, the exact reason for the admission was unknown. In addition, many admissions did not have any diagnosis code or procedure code available. It is possible that individual GMFCS level might change over time and the level recorded on the CP register at the time of data extraction may differ from the functional ability of the child or young person at each admission. This analysis was limited to data from tertiary paediatric hospitals only; patterns of use of these hospitals are likely to differ from that of nonpaediatric hospitals. The high rate of elective and surgical admissions are reflective of this. The available data did not enable the identification of preventable readmissions, nor do we not have information on readmissions to different hospitals which likely leads to an undercounting of readmissions. As such, investigating the patterns of admission to all hospitals is an important area for future research. It would offer a greater insight into the frequency and type of admissions and readmissions in the $\mathrm{CP}$ population, and could inform strategies to reduce unnecessary inpatient resource use in this group.

The strengths of this study lie in the use of a population-based CP register as a sampling frame and the availability of data on CP severity and complexity. Such data would not have been available had we used administrative data only and identified children with CP via ICD codes. This study adds to the existing literature by providing new information on risk factors for frequency and type of hospital admissions in the CP population. It offers new insights into the use of inpatient services by children and young people with CP in Australia, and highlights priority areas for prevention, early diagnosis and management as well as future research, thus having implications for researchers and clinicians.

\section{Acknowledgements}

The authors gratefully acknowledge individuals on the Victorian Cerebral Palsy Register and their families for their ongoing support and willingness to participate in research projects. We also acknowledge staff from the Health Information Services departments of both hospitals. Funding for the Victorian Cerebral Palsy Register was provided by the Victorian Department of Health, and infrastructure support was provided by the Victorian Government's Operational Infrastructure Support Program. The first author received funding through a PhD stipend from Murdoch Childrens Research Institute and an international student scholarship from the University of Melbourne. 
Adams, S., Cohen, E., Mahant, S., Friedman, J. N., Macculloch, R. \& Nicholas, D. B. (2013) Exploring the usefulness of comprehensive care plans for children with medical complexity (CMC): a qualitative study. BMC Pediatrics, 13, 10.

Alverson, B. K. \& O' Callaghan, J. (2013) Hospital readmission: quality indicator or statistical inevitability? Pediatrics, 132, 569-570.

Antonelli, R. C., Stille, C. J. \& Antonelli, D. M. (2008) Care coordination for children and youth with special health care needs: a descriptive, multisite study of activities, personnel costs, and outcomes. Pediatrics, 122, e209-216.

Ashton, C. M., Del Junco, D. J., Souchek, J., Wray, N. P. \& Mansyur, C. L. (1997) The association between the quality of inpatient care and early readmission: a meta-analysis of the evidence. Medical Care, 35, 1044-1059.

Australian Institute of Health and Welfare (2014) Australian hospital statistics 2012-13. Health services series no. 54. Cat. no. HSE 145. AlHW, Canberra.

Bardach, N. S., Vittinghoff, E., Asteria-Penaloza, R., Edwards, J. D., Yazdany, J., Lee, H. C., Boscardin, W. J., Cabana, M. D. \& Dudley, R. A. (2013) Measuring hospital quality using pediatric readmission and revisit rates. Pediatrics, 132, 429-436.

Berry, J. G., Hall, D. E., Kuo, D. Z., Cohen, E., Agrawal, R., Feudtner, C., Hall, M., Kueser, J., Kaplan, W. \& Neff, J. (2011) Hospital Utilization and Characteristics of Patients Experiencing Recurrent Readmissions Within Children's Hospitals. Journal of the American Medical Association, 305, 682-690.

Berry, J. G., Hall, M., Hall, D. E., Kuo, D. Z., Cohen, E., Agrawal, R., Mandl, K. D., Clifton, H. \& Neff, J. (2012a) Inpatient Growth and Resource Use in 28 Children's Hospitals: A Longitudinal, Multiinstitutional Study. Archives of Pediatrics and Adolescent Medicine, 1-9.

Berry, J. G., Poduri, A., Bonkowsky, J. L., Zhou, J., Graham, D. A., Welch, C., Putney, H. \& Srivastava, R. (2012b) Trends in resource utilization by children with neurological impairment in the United States inpatient health care system: a repeat cross-sectional study. PLoS Medicine, 9, e1001158.

Berry, J. G., Toomey, S. L., Zaslavsky, A. M., Jha, A. K., Nakamura, M. M., Klein, D. J., Feng, J. Y., Shulman, S., Chiang, V. W., Kaplan, W., Hall, M. \& Schuster, M. A. (2013) Pediatric readmission prevalence and variability across hospitals. Journal of the American Medical Association, 309, 372-380.

Cohen, E., Lacombe-Duncan, A., Spalding, K., Macinnis, J., Nicholas, D., Narayanan, U. G., Gordon, M., Margolis, I. \& Friedman, J. N. (2012) Integrated complex care coordination for children with medical complexity: a mixed-methods evaluation of tertiary care-community collaboration. BMC Health Services Research, 12, 366. 
Commonwealth of Australia (2010) The Australian Classification of Health Interventions (ACHI). Tabular list of interventions, National Centre for Classification in Health, Faculty of Health Sciences, The University of Sydney, Sydney.

Dahlseng, M. O., Andersen, G. L., M, D. a. G. A., Arnaud, C., Balu, R., De La Cruz, J., Folha, T., Himmelmann, K., Horridge, K., Juliusson, P. B., Pahlman, M., Rackauskaite, G., Sigurdardottir, S., Uldall, P. \& Vik, T. (2012) Gastrostomy tube feeding of children with cerebral palsy: variation across six European countries. Developmental Medicine and Child Neurology, 54, 938-944.

Doyle, L. W. \& The Victorian Infant Collaborative Study Group (2004) Evaluation of Neonatal Intensive Care for Extremely Low Birth Weight Infants in Victoria Over Two Decades: I. Effectiveness. Pediatrics, 113, 505-509.

Graham, H. K. \& Selber, P. (2003) Musculoskeletal aspects of cerebral palsy. Journal of Bone and Joint Surgery - British Volume, 85, 157-166.

Kaiser, J. R., Tilford, J. M., Simpson, P. M., Salhab, W. A. \& Rosenfeld, C. R. (2004) Hospital Survival of Very-Low-Birth-Weight Neonates from 1977 to 2000. Journal of Perinatology, 24, 343-350.

Mccrea, N., O'donnell, R. \& Brown, R. (2013) Outpatient respiratory management of the child with severe neurological impairment. Archives of disease in childhood - Education \& practice edition, 98, 84-91.

Murphy, N. A., Hoff, C., Jorgensen, T., Norlin, C. \& Young, P. C. (2006) Costs and complications of hospitalizations for children with cerebral palsy. Developmental Neurorehabilitation, 9, 4752.

Nakamura, M. M., Toomey, S. L., Zaslavsky, A. M., Berry, J. G., Lorch, S. A., Jha, A. K., Bryant, M. C., Geanacopoulos, A. T., Loren, S. S., Pain, D. \& Schuster, M. A. (2014) Measuring pediatric hospital readmission rates to drive quality improvement. Academic Pediatrics, 14, S39-46.

Oskoui, M., Coutinho, F., Dykeman, J., Jetté, N. \& Pringsheim, T. (2013) An update on the prevalence of cerebral palsy: a systematic review and meta-analysis. Developmental Medicine and Child Neurology, 55, 509-519.

Palisano, R. J., Rosenbaum, P. L., Walter, S., Russell, D., Wood, E. \& Galuppi, B. (1997) Development and reliability of a system to classify gross motor function in children with cerebral palsy. Developmental Medicine and Child Neurology, 39, 214-223.

Pruitt, D. W. \& Tsai, T. (2009) Common medical comorbidities associated with cerebral palsy. Physical Medicine and Rehabilitation Clinics of North America, 20, 453-467.

Quigley, L., Lacombe-Duncan, A., Adams, S., Hepburn, C. M. \& Cohen, E. (2014) A qualitative analysis of information sharing for children with medical complexity within and across health care organizations. BMC Health Services Research, 14, 283. 
Reid, S. M., Carlin, J. B. \& Reddihough, D. S. (2012) Survival of individuals with cerebral palsy born in Victoria, Australia, between 1970 and 2004. Developmental Medicine and Child Neurology, 54, 353-360.

Rosenbaum, P. L., Paneth, N., Leviton, A., Goldstein, M., Bax, M., Damiano, D., Dan, B. \& Jacobsson, B. (2007) A report: the definition and classification of cerebral palsy April 2006. Developmental Medicine and Child Neurology Supplement, 109, 8-14.

Shevell, M. I., Dagenais, L. \& Hall, N. (2009) Comorbidities in cerebral palsy and their relationship to neurologic subtype and GMFCS level. Neurology, 72, 2090-2096.

Simon, T. D., Berry, J., Feudtner, C., Stone, B. L., Sheng, X., Bratton, S. L., Dean, J. M. \& Srivastava, R. (2010) Children with complex chronic conditions in inpatient hospital settings in the United States. Pediatrics, 126, 647-655.

Statacorp. (2013) Stata Statistical Software: Release 13. StataCorp LP, College Station, TX.

World Health Organisation (2011) ICD-10 International Statistical Classification of Diseases and Related Health Problems 10th Revision, Geneva.

Young, N. L., Gilbert, T. K., Mccormick, A., Ayling-Campos, A., Boydell, K., Law, M., Fehlings, D. L., Mukherjee, S., Wedge, J. H. \& Williams, J. I. (2007) Youth and Young Adults With Cerebral Palsy: Their Use of Physician and Hospital Services. Archives of Physical Medicine and Rehabilitation, 88, 696-702.

Young, N. L., Mccormick, A. M., Gilbert, T., Ayling-Campos, A., Burke, T., Fehlings, D. \& Wedge, J. (2011) Reasons for Hospital Admissions Among Youth and Young Adults With Cerebral Palsy. Archives of Physical Medicine and Rehabilitation, 92, 46-50. 
Tables

Table 1: Number of admissions, 2008-2012, by GMFCS level and epilepsy

\begin{tabular}{|c|c|c|c|c|c|c|c|c|c|c|}
\hline & \multicolumn{10}{|c|}{ GMFCS level } \\
\hline & \multicolumn{4}{|c|}{$\begin{array}{c}\mathrm{I} / \mathrm{II} \\
(\mathrm{n}=1317)\end{array}$} & \multicolumn{4}{|c|}{$\begin{array}{c}\text { III-V } \\
(n=783)\end{array}$} & \multirow[b]{2}{*}{ Wilcoxon's Z $^{\#}$} & \multirow[b]{2}{*}{$p$-value ${ }^{\#}$} \\
\hline & Min. & Max. & Median & IQR & Min. & Max. & Median & IQR & & \\
\hline All & 0 & 36 & 1 & $0-3$ & 0 & 50 & 3 & $1-7$ & -13.634 & $<0.0001$ \\
\hline Same-day & 0 & 32 & 0 & $0-2$ & 0 & 26 & 1 & $0-3$ & -6.286 & $<0.0001$ \\
\hline \multirow[t]{4}{*}{ Multi-day } & 0 & 14 & 0 & $0-1$ & 0 & 50 & 2 & $0-4$ & -18.362 & $<0.0001$ \\
\hline & \multicolumn{10}{|c|}{ Epilepsy } \\
\hline & \multicolumn{4}{|c|}{$\begin{array}{c}\text { No } \\
(n=1476)\end{array}$} & \multicolumn{4}{|c|}{$\begin{array}{c}\text { Yes } \\
(n=623)\end{array}$} & & \\
\hline & Min. & Max. & Median & IQR & Min. & Max. & Median & IQR & Wilcoxon's Z & $p$-value ${ }^{\#}$ \\
\hline All & 0 & 50 & 1 & $0-4$ & 0 & 41 & 3 & $1-7$ & -9.674 & $<0.0001$ \\
\hline Same-day & 0 & 32 & 0 & $0-2$ & 0 & 30 & 1 & $0-3$ & -5.673 & $<0.0001$ \\
\hline Multi-day & 0 & 50 & 0 & $0-1$ & 0 & 39 & 1 & $0-4$ & -12.308 & $<0.0001$ \\
\hline
\end{tabular}

Members of the cohort for whom data on GMFCS level and epilepsy were missing were excluded from analysis.

\#From Mann-Whitney test

GMFCS, Gross Motor Function Classification System; Min, minimum; Max, maximum; IQR, interquartile range: indicates range from $25^{\text {th }}$ to $75^{\text {th }}$ percentile.

Table 2: Multi-day admissions: number of admitted nights, and median length of stay by GMFCS, epilepsy status and ARDRG type

\begin{tabular}{|c|c|c|c|c|c|c|c|c|c|c|}
\hline & & & & 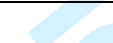 & \multicolumn{6}{|c|}{ Length of stay (days) } \\
\hline & \multicolumn{2}{|c|}{$\begin{array}{l}\text { Multi-day } \\
\text { admissions }\end{array}$} & \multicolumn{2}{|c|}{ Admitted nights } & Min. & Max. & Median & IQR & Wilcoxon's Z & $p$-value $\#$ \\
\hline & $n$ & (\%) & $\mathbf{n}$ & (\%) & 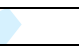 & & & & & \\
\hline Total & 3440 & $(100.0)$ & 21955 & $(100.0)$ & 1 & 242 & 3 & $1-3$ & & \\
\hline GMFCS & & & & & & & & & -10.953 & $<0.0001$ \\
\hline $1 / I I$ & 994 & $(30.0)$ & 4600 & $(21.0)$ & 1 & 132 & 2 & $1-5$ & & \\
\hline III-V & 2324 & $(70.0))$ & 16523 & (75.3) & 1 & 242 & 4 & $2-7$ & & \\
\hline Unknown & 122 & & & & & & & & & \\
\hline Epilepsy & & & & & & & & & -2.457 & 0.014 \\
\hline Yes & 1792 & $(53.0)$ & 11585 & (52.8) & 1 & 173 & 3 & $2-7$ & & \\
\hline No & 1590 & $(47.0)$ & 10085 & $(46.0)$ & 1 & 242 & 3 & $1-6$ & & \\
\hline Unknown & 58 & & & & & & & & & \\
\hline AR-DRG type & & & & & & & & & -4.037 & 0.0001 \\
\hline Medical & 1636 & (56.3) & 9508 & (43.3) & 1 & 242 & 3 & $1-6$ & & \\
\hline Surgical & 1269 & (43.7) & 8571 & (39.0) & 1 & 211 & 4 & $2-6$ & & \\
\hline Other/Unknown & 535 & & & & & & & & & \\
\hline
\end{tabular}

Admissions with missing data on GMFCS level, epilepsy and AR-DRG type were excluded from analysis.

\# From Mann-Whitney test

GMFCS, Gross Motor Function Classification System; AR-DRG, Australian-Refined Diagnostic Related Group; Min, minimum; Max, maximum; IQR, interquartile range: indicates range from $25^{\text {th }}$ to $75^{\text {th }}$ percentile. 
Table 3: Variation in primary diagnosis of multi-day admissions according to GMFCS level

\begin{tabular}{|c|c|c|c|c|c|c|c|c|}
\hline & \multicolumn{8}{|c|}{ AR-DRG type } \\
\hline & \multicolumn{4}{|c|}{$\begin{array}{l}\text { Medical }^{a} \\
(n=1572)\end{array}$} & \multicolumn{4}{|c|}{$\begin{array}{l}\text { Surgical }^{b} \\
(n=1237)\end{array}$} \\
\hline & \multicolumn{2}{|c|}{ GMFCS I/II } & \multicolumn{2}{|c|}{ GMFCS III-V } & \multicolumn{2}{|c|}{ GMFCS I/II } & \multicolumn{2}{|c|}{ GMFCS III-V } \\
\hline & & (\%) & & (\%) & & $(\%)$ & $\mathbf{n}$ & (\%) \\
\hline All $^{\#}$ & 405 & $(25.8)$ & 1167 & (74.2) & 453 & (36.6) & 784 & (63.4) \\
\hline Infectious and parasitic diseases & 17 & $(4.2)$ & 82 & $(7.0)$ & 0 & (0) & 7 & $(0.9)$ \\
\hline Nervous system diseases & 63 & $(15.6)$ & 185 & (15.9) & 43 & $(9.5)$ & 56 & $(7.1)$ \\
\hline Cerebral palsy & 13 & $(3.2)$ & 36 & (3.1) & 25 & $(5.5)$ & 34 & $(4.3)$ \\
\hline Epilepsy & 33 & $(8.1)$ & 114 & $(9.8)$ & 1 & $(0.2)$ & 2 & $(0.3)$ \\
\hline Other nervous system & 17 & $(4.2)$ & 35 & $(3.0)$ & 17 & $(3.8)$ & 20 & $(2.6)$ \\
\hline Respiratory diseases & 49 & (12.1) & 275 & $(23.6)$ & 11 & $(2.4)$ & 35 & $(4.5)$ \\
\hline Disease of the upper respiratory tract & 12 & $(3.0)$ & 41 & $(3.6)$ & 10 & $(2.2)$ & 14 & $(1.8)$ \\
\hline Diseases of the lower respiratory tract & 37 & $(9.2)$ & 221 & $(19.0)$ & & $(0.2)$ & 13 & $(1.7)$ \\
\hline Other respiratory & 0 & $(0)$ & 13 & $(1.1)$ & 0 & $(0)$ & 8 & $(1.0)$ \\
\hline Digestive diseases & 16 & $(4.0)$ & 68 & $(5.8)$ & 11 & $(2.4)$ & 48 & $(6.1)$ \\
\hline Musculoskeletal diseases & 7 & $(1.7)$ & 35 & $(3.0)$ & 195 & (43.1) & 366 & (46.7) \\
\hline Contracture of muscle or tendon & 0 & $(0)$ & 5 & $(0.4)$ & 111 & $(24.5)$ & 181 & $(23.1)$ \\
\hline Joint derangement & 0 & (0) & 4 & $(0.3)$ & 25 & $(5.5)$ & 81 & $(10.3)$ \\
\hline Acquired deformity & 1 & $(0.3)$ & 0 & $(0)$ & 50 & $(11.0)$ & 57 & $(7.3)$ \\
\hline Scoliosis & 0 & $(0)$ & 1 & $(0.1)$ & & (0) & 37 & $(4.7)$ \\
\hline Other musculoskeletal & 6 & $(1.5)$ & 25 & $(2.2)$ & & $(2.0)$ & 10 & $(1.3)$ \\
\hline Symptoms, signs \& abnormal findings, NEC & 39 & $(9.6)$ & 158 & (13.5) & 4 & $(0.9)$ & 18 & $(2.3)$ \\
\hline Symptoms \& signs involving digestive system \& abdomen & 9 & $(2.2)$ & 56 & $(4.8)$ & 0 & $(0)$ & 4 & $(0.5)$ \\
\hline Convulsions & 6 & $(1.5)$ & 23 & $(2.0)$ & 0 & $(0)$ & 0 & $(0)$ \\
\hline Other symptoms or signs & 24 & $(5.9)$ & 80 & $(6.9)$ & 4 & $(0.9)$ & 14 & $(1.8)$ \\
\hline Injury, poisoning and consequences of external causes & 17 & $(4.2)$ & 41 & $(3.5)$ & & $(10.4)$ & 54 & $(6.9)$ \\
\hline Factors influencing health $\&$ contact with health services & 62 & $(15.3)$ & 112 & (9.6) & 33 & (7.3) & 63 & $(8.0)$ \\
\hline Other orthopaedic follow-up care & 3 & $(0.7)$ & 9 & $(0.8)$ & 27 & $(6.0)$ & 52 & $(6.6)$ \\
\hline Care involving rehabilitation procedures & 40 & $(9.9)$ & & $(4.4)$ & 0 & $(0)$ & 0 & $(0)$ \\
\hline Attention to artificial opening or implanted device & 2 & $(0.5)$ & 8 & $(0.7)$ & 6 & $(1.3)$ & 7 & $(0.9)$ \\
\hline Other factors & 17 & $(4.2)$ & 44 & $(3.8)$ & & $(0)$ & 4 & $(0.5)$ \\
\hline Other * & 43 & $(10.6)$ & 89 & $(7.6)$ & 48 & (10.6) & 66 & $(8.4)$ \\
\hline No diagnosis listed & 92 & $(22.7)$ & 122 & (10.5) & 61 & (13.5) & 71 & (9.1) \\
\hline
\end{tabular}

Admissions with missing data on GMFCS level were excluded from analysis.

${ }^{a} \chi^{2}(9, \quad N=1572)=76.13, p<0.001$ (for test of difference in major diagnostic category of overnight medical admissions between individuals classified as GMFCS I/II and those classified as GMFCS III-V).

${ }^{b} \chi^{2}(9, N=1237)=32.69, p<0.001$ (for test of difference in major diagnostic category of overnight surgical admission between individuals classified as GMFCS I/II and those classified as GMFCS III-V).

* Neoplasms; diseases of the blood and blood forming organs and immune mechanism; endocrine, nutritional and metabolic diseases; mental and behavioural disorders; diseases of the eye and adnexa; diseases of the ear and mastoid; circulatory system diseases; genitourinary system diseases; diseases of the skin and subcutaneous tissue; certain conditions originating in the perinatal period; and congenital anomalies

AR-DRG, Australian-Refined Diagnostic Related Group; GMFCS, Gross Motor Function Classification System; NEC, Not elsewhere classified; GI, Gastrointestinal. 


\begin{tabular}{|c|c|c|c|c|c|c|c|c|}
\hline & \multicolumn{4}{|c|}{ Length of admission $^{\mathrm{a}}$} & \multicolumn{4}{|c|}{ GMFCS level $^{\text {b }}$} \\
\hline & \multicolumn{2}{|c|}{$\begin{array}{c}\text { Same-day } \\
\text { (3737) }\end{array}$} & \multicolumn{2}{|c|}{$\begin{array}{c}\text { Multi-day } \\
\text { (3440) }\end{array}$} & \multicolumn{2}{|c|}{$\begin{array}{c}1 / 11 \\
(3050)\end{array}$} & \multicolumn{2}{|c|}{$\begin{array}{c}\text { III-V } \\
(3920)\end{array}$} \\
\hline & $\mathbf{n}$ & $(\%)$ & $\mathbf{n}$ & (\%) & $\mathbf{n}$ & (\%) & $\mathbf{n}$ & (\%) \\
\hline Musculoskeletal procedure & 1857 & (49.7) & 877 & $(25.5)$ & 1639 & (53.8) & 1053 & (26.8) \\
\hline Administration of agent into musculoskeletal site & 1757 & $(47.0)$ & 34 & $(1.0)$ & 1264 & $(41.4)$ & 498 & (12.7) \\
\hline Procedure on hip & 8 & $(0.2)$ & 321 & $(9.3)$ & 91 & (3.0) & 235 & $(6.0)$ \\
\hline Procedure on leg & 13 & $(0.4)$ & 211 & $(6.1)$ & 137 & $(4.5)$ & 85 & $(2.2)$ \\
\hline Spinal procedure & 0 & (0) & 38 & $(1.1)$ & 0 & (0) & 37 & (0.9) \\
\hline Other application, insertion or removal procedure & 36 & $(1.0)$ & 121 & $(3.5)$ & 57 & (1.9) & 97 & $(2.5)$ \\
\hline Procedure on upper limb & 13 & $(0.4)$ & 10 & $(0.3)$ & 18 & $(0.6)$ & 5 & $(0.1)$ \\
\hline Other musculoskeletal procedure & 29 & $(0.8)$ & 142 & $(4.1)$ & 72 & (2.4) & 96 & (2.5) \\
\hline Procedure on digestive system & 321 & (8.6) & 164 & $(4.8)$ & 64 & (2.1) & 412 & (10.5) \\
\hline Application, insertion or removal procedure on stomach & 227 & $(6.1)$ & 80 & $(2.3)$ & 20 & $(0.7)$ & 281 & $(7.2)$ \\
\hline Panendoscopy & 77 & $(2.1)$ & 14 & $(0.4)$ & 16 & $(0.5)$ & 75 & (1.9) \\
\hline Fundoplication & 0 & (0) & 36 & $(1.0)$ & 0 & 0 & 33 & $(0.8)$ \\
\hline Other procedure on digestive system & 17 & $(0.5)$ & 34 & $(1.0)$ & 28 & (0.9) & 23 & (0.6) \\
\hline Procedure on nervous system & 35 & (0.9) & 161 & (4.7) & 62 & (2.0) & 131 & (3.3) \\
\hline Revision of intracranial cerebrospinal fluid shunt & 0 & (0) & 54 & $(1.6)$ & 29 & (1.0) & 25 & $(0.6)$ \\
\hline Cranial tap or puncture & 21 & $(0.6)$ & 27 & $(0.8)$ & 15 & $(0.5)$ & 31 & $(0.8)$ \\
\hline Insertion of spinal catheter, infusion device or pump & 0 & (0) & 26 & $(0.8)$ & 2 & $(0.1)$ & 24 & (0.6) \\
\hline Revision procedures on spinal canal or spinal cord & 0 & $(0)$ & 17 & $(0.5)$ & 0 & (0) & 17 & $(0.4)$ \\
\hline Other procedure on nervous system & 14 & $(0.3)$ & 37 & $(3.7)$ & 16 & $(0.4)$ & 34 & (0.9) \\
\hline Procedure on respiratory system & 8 & $(0.2)$ & 174 & $(5.1)$ & 23 & $(0.8)$ & 155 & (4.0) \\
\hline Ventilatory support & 2 & (0.1) & 130 & $(3.8)$ & 16 & $(0.5)$ & 113 & (2.9) \\
\hline Airway management & 2 & (0.1) & 19 & $(0.6)$ & 3 & $(0.1)$ & 18 & $(0.5)$ \\
\hline Other procedure on respiratory system & 6 & $(0.1)$ & 25 & $(0.7)$ & 4 & $(0.2)$ & 24 & (0.6) \\
\hline Dental procedure & 165 & (4.4) & 20 & $(0.6)$ & 49 & (1.6) & 135 & (3.4) \\
\hline Non-invasive, cognitive and other interventions, NEC & 336 & (9.0) & 763 & $(22.2)$ & 280 & (9.2) & 805 & (20.5) \\
\hline Intervention involving device, aid or equipment & 107 & (2.9) & 22 & $(0.6)$ & 61 & (2.0) & 67 & $(1.7)$ \\
\hline Generalised allied health intervention & 8 & $(0.2)$ & 584 & $(17.0)$ & 90 & (3.0) & 498 & (12.7) \\
\hline Administration of pharmacotherapy & 145 & (3.9) & 24 & $(0.7)$ & 43 & (1.4) & 125 & $(3.2)$ \\
\hline Other non-invasive, cognitive and other interventions & 76 & $(2.0)$ & 133 & (3.9) & 86 & $(2.8)$ & 115 & (2.9) \\
\hline Imaging services & 86 & (2.3) & 115 & (3.3) & 70 & (2.3) & 126 & (3.2) \\
\hline Other * & 166 & (4.4) & 167 & (4.9) & 177 & (5.8) & 154 & (3.9) \\
\hline No procedure listed & 763 & (20.4) & 999 & $(29.0)$ & 686 & $(22.5)$ & 949 & (24.2) \\
\hline
\end{tabular}

Admissions with missing data on GMFCS level were excluded from analysis.

${ }^{a} \chi^{2}(8, N=7177)=939.17, p=<0.001$ (test for difference between same-day and multi-day admissions in category of primary procedure carried out during admission).

${ }^{\mathrm{b}} \chi^{2}(8, N=6970)=761.95, p=<0.001$ (for difference between individuals classified as GMFCS I/II and those classified as GMFCS III-V in category of primary procedure carried out during admission).

* Procedures on endocrine system; eye and adnexa; ear and mastoid process; nose, mouth and pharynx; cardiovascular system; blood and blood-forming organs; urinary system; male genital organs; gynaecological procedures; dermatological and plastic procedures; and breast.

GMFCS, Gross Motor Function Classification System; NEC, not elsewhere classified. 
Table 5: 7-day, 30-day and 365-day all-cause readmission rates for all multi-day emergency admissions

\begin{tabular}{|c|c|c|c|}
\hline & 7-day & 30-day & 365-day \\
\hline All & $10.2 \%$ & 22.6 & $63.4 \%$ \\
\hline Age (years) at admission & $\begin{array}{c}\mathrm{X}^{2}(3, \mathrm{~N}=1630)=3.49 \\
p=0.322\end{array}$ & $\begin{array}{c}\chi^{2}(3, N=1609)=7.79 \\
p=0.051\end{array}$ & $\begin{array}{c}\chi^{2}(3, N=1340)=9.62 \\
p=0.022\end{array}$ \\
\hline $0-4$ & $10.2 \%$ & $24.1 \%$ & 66.9 \\
\hline $5-9$ & $11.4 \%$ & $24.6 \%$ & 63.3 \\
\hline $10-14$ & $8.2 \%$ & $17.8 \%$ & 61.2 \\
\hline $15-19$ & $12.3 \%$ & $24.5 \%$ & 51.5 \\
\hline GMFCS level & $\begin{array}{c}\mathrm{X}^{2}(1, \mathrm{~N}=1561)=0.01 \\
p=0.916\end{array}$ & $\begin{array}{c}\chi^{2}(1, N=1541)=12.22 \\
p<0.0001\end{array}$ & $\begin{array}{c}\chi^{2}(1, N=1281)=52.11 \\
p<0.0001\end{array}$ \\
\hline $1 / 11$ & $10.2 \%$ & $15.5 \%$ & $44.9 \%$ \\
\hline III-V & $10.4 \%$ & $24.4 \%$ & $68.1 \%$ \\
\hline AR-DRG type & $\begin{array}{c}\mathrm{X}^{2}(1, \mathrm{~N}=1339)=0.49 \\
p=0.486\end{array}$ & $\begin{array}{c}\chi^{2}(1, N=1320)=1.95 \\
p=0.163\end{array}$ & $\begin{array}{c}\chi^{2}(1, N=1109)=0.50 \\
p=0.479\end{array}$ \\
\hline Medical & $10.5 \%$ & $23.9 \%$ & $64.5 \%$ \\
\hline Surgical & $12.4 \%$ & $28.9 \%$ & $61.4 \%$ \\
\hline Primary diagnosis category of index admission & $\begin{array}{c}\mathrm{X}^{2}(8, \mathrm{~N}=1407)=33.44 \\
p<0.0001\end{array}$ & $\begin{array}{c}\chi^{2}(8, N=1,389)=19.86 \\
p=0.011\end{array}$ & $\begin{array}{c}\chi^{2}(8, N=1147)=32.38 \\
p<0.0001\end{array}$ \\
\hline Infectious and parasitic diseases & $5.6 \%$ & $22.4 \%$ & $55.4 \%$ \\
\hline Nervous system diseases & $6.9 \%$ & $18.9 \%$ & $64.1 \%$ \\
\hline Respiratory system diseases & $9.3 \%$ & $22.0 \%$ & $71.4 \%$ \\
\hline Digestive system diseases & $11.3 \%$ & $22.1 \%$ & $53.4 \%$ \\
\hline Musculoskeletal diseases & $5.4 \%$ & $18.9 \%$ & $50.0 \%$ \\
\hline Symptoms, signs and abnormal findings NEC & $19.9 \%$ & $32.5 \%$ & $70.6 \%$ \\
\hline Injury, poisoning and consequences of external causes & $15.6 \%$ & $26.5 \%$ & $57.0 \%$ \\
\hline $\begin{array}{l}\text { Factors influencing health and contact with health } \\
\text { services }\end{array}$ & $0 \%$ & $3.7 \%$ & $34.8 \%$ \\
\hline Other & $10.8 \%$ & 23.4 & $60.9 \%$ \\
\hline
\end{tabular}

Admissions with missing data on GMFCS level, AR-DRG type and primary diagnosis category of index admission were excluded from analysis.

$\mathrm{X}^{2}$ testing for differences between sub-groups of age, GMFCS, AR-DRG, and primary diagnosis category in the proportion of 7-, 30-, and 365-day readmissions: $X^{2}$ (degrees of freedom, sample size) $=X^{2}$ statistic, $p$-value

GMFCS, Gross Motor Function Classification System; AR-DRG, Australian Refined Diagnostic Related Group; NEC, not elsewhere classified 


\section{University Library}

\section{- M M N E R VA A gateway to Melbourne's research publications}

Minerva Access is the Institutional Repository of The University of Melbourne

\section{Author/s:}

Meehan, E;Freed, GL;Reid, SM;Williams, K;Sewell, JR;Rawicki, B;Reddihough, DS

Title:

Tertiary paediatric hospital admissions in children and young people with cerebral palsy

Date:

2015-11-01

Citation:

Meehan, E., Freed, G. L., Reid, S. M., Williams, K., Sewell, J. R., Rawicki, B. \& Reddihough, D. S. (2015). Tertiary paediatric hospital admissions in children and young people with cerebral palsy. CHILD CARE HEALTH AND DEVELOPMENT, 41 (6), pp.928-937. https:// doi.org/10.1111/cch.12263.

Persistent Link:

http://hdl.handle.net/11343/116026 